\title{
Duração e cálculo: reflexões de alguns compositores entre as décadas de 1930 e 1960
}

Marcos Mesquita

(Universidade Estadual Paulista)

Resumo: o texto discute, compara e critica reflexões de alguns compositores do século XX sobre a ordenação do parâmetro da duração. Tais reflexões foram importantes especialmente no decorrer da década de 1950 para estabelecimento do assim chamado serialismo integral e da música estocástica.

Palavras-chave: relações altura/duração, serialismo integral da década de 1950, música estocástica.

DURATION AND CALCULATION: SOME COMPOSER'S CONSIDERATIONS BETWEEN 1930 AND 1960

Abstract: this text examines, compare and criticizes the reflections by some composers of the $20^{\text {th }}$ Century about the length parameter. These reflections were important especially during the 1950's decade in order to establish the so-called integral serialism and the stochastic music.

Keywords: pitch/length connections, integral serialism in the 1950's, stochastic music. 


\section{Introdução}

A partir das últimas décadas do século XIX, todos os elementos composicionais da música sofreram uma reavaliação fundamental, resultando daí inúmeras novas possibilidades criativas. Quando mencionamos o nome de Claude Debussy, por exemplo, temos o hábito de associá-lo à libertação das regras da harmonia tradicional, à busca de novas harmonias, novos timbres harmônicos. Mas a estrutura rítmica de sua música também causou impacto em sua época. Basta lembrarmos os "ensaios longos e laboriosos" para a primeira audição de seu Prélude à l'aprés-midi d'un faune sob regência de Gustave Doret (Vallas, 1958, p. 179). Já na primeira metade do século $X X$, o ritmo, ou melhor dizendo, o parâmetro da duração, passa a ser estruturado de diferentes maneiras, absorvendo ritmos irregulares criados pela própria imaginação dos compositores ou oriundos de fontes étnico-musicais. Após a Segunda Guerra Mundial, os procedimentos de serialização, antes aplicados somente ao parâmetro da altura, foram projetados para outros parâmetros. O que isto significou para a estruturação rítmica da música criada no contexto do serialismo integral será avaliado e criticado nas páginas seguintes.

I.

Em consequência da decomposição dos parâmetros do som na música serial da década de 1950, Gottfried Michael Koenig escreveu sobre a duração, respectivamente a sucessão de valores rítmicos:

O caráter temporal da música se emancipou tanto hoje [...], que se faz necessário examinar a relação das diferentes durações entre si, como se definiu até hoje somente as relações de diferentes tons de melodia ou diferentes vozes entre si. A duração de um som tornou-se [...] uma categoria autônoma. Consequentemente uma sequência de durações pode conter tanto sentido musical quanto uma sequência de valores dinâmicos ou acordes ou timbres (Koenig, 1962, p. 76). 
A serialização da duração por meio de tabelas numéricas simples, uma estratégia utilizada por vários compositores para carregar uma sequência de durações de "sentido musical", provocou críticas enérgicas:

Infelizmente, com a escola pós-guerra [Segunda Guerra Mundial], surgiu um novo tipo de pitagorismo, levando à aplicação de proporções matemáticas simples e permutações de divisões de tempo que, com o auxílio de divisões mais "irracionais" de valores, dá a impressão de irregularidade permanente sob um ponto de vista totalmente diferente, um ponto de vista experimental ou uma "dissociação dos sentidos" (Rimbaud), e a maneira de lidar com tempo e memória tornou-se muito óbvia, quase primitiva. As coisas continuam por um tempo de um modo mais ou menos uniforme e, então, mudam para um trecho de conceito similar. Isso é, de fato, uma negação de memória e tempo que corresponde ao tratamento [...] que recebemos como leitores de jornais ou propaganda, como alvos de quase qualquer tipo de mensagem que reduz tudo à superficialidade e, no final das contas, à perda de identidade (Carter, 1997, p. 318).

A partir do final da década de 1940, especialmente desde Three Compositions for Piano (1947) de Milton Babbitt (Kostka, 2006, p. 265-267) e Mode de Valeurs et d'Intensités (1949) de Olivier Messiaen, vários compositores vão se empenhar em estabelecer uma ordenação estrutural abrangendo outros parâmetros sonoros além da altura que já vinha sendo ordenada serialmente desde o advento do dodecafonismo. O serialismo integral tentará estabelecer tal ordem, em princípio de maneira um tanto quanto ingênua. Essa supraordenação dos eventos sonoros vai inicialmente transferir a responsabilidade compositiva do compositor para uma outra esfera, geralmente uma matriz numérica que será aplicada a outros parâmetros tradicionais do som além da altura como, por exemplo, duração, intensidade e articulação. Nesse sentido, a matriz serial de Structures la (1952) para dois pianos de Pierre Boulez é relativamente simples e pode ser explanada rapidamente - tal matriz foi desvendada por György Ligeti em artigo publicado em 1958 (Ligeti, 1958, p. 38-63). 
II.

Boulez parte de uma das séries dodecafônicas que fora utilizada em Mode de Valeurs et d'Intensités, acrescentando sua inversão:

Ex. 1. Séries de Structures / de Pierre Boulez

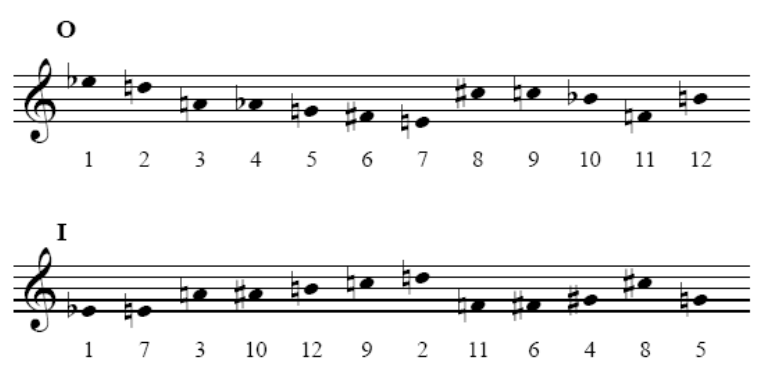

A partir delas, Boulez constrói duas tabelas cujos números vão ordenar além das alturas, as durações, intensidades e articulações (os algarismos das tabelas referem-se aos sons tal qual eles foram numerados na série original: mib $=1$, ré $=2$ etc.):

Tabela 1. Quadrados seriais de Structures la de Pierre Boulez

Original $\rightarrow$

\begin{tabular}{|l|l|l|l|l|l|l|l|l|l|l|l|}
\hline 1 & 2 & 3 & 4 & 5 & 6 & 7 & 8 & 9 & 10 & 11 & 12 \\
\hline 2 & 8 & 4 & 5 & 6 & 11 & 1 & 9 & 12 & 3 & 7 & 10 \\
\hline 3 & 4 & 1 & 2 & 8 & 9 & 10 & 5 & 6 & 7 & 12 & 11 \\
\hline 4 & 5 & 2 & 8 & 9 & 12 & 3 & 6 & 11 & 1 & 10 & 7 \\
\hline 5 & 6 & 8 & 9 & 12 & 10 & 4 & 11 & 7 & 2 & 3 & 1 \\
\hline 6 & 11 & 9 & 12 & 10 & 3 & 5 & 7 & 2 & 8 & 4 & 2 \\
\hline 7 & 1 & 10 & 3 & 4 & 5 & 11 & 2 & 12 & 12 & 6 & 9 \\
\hline 8 & 9 & 5 & 6 & 11 & 7 & 2 & 12 & 10 & 4 & 1 & 3 \\
\hline 9 & 12 & 6 & 11 & 7 & 1 & 8 & 10 & 3 & 5 & 2 & 4 \\
\hline 10 & 3 & 7 & 1 & 2 & 8 & 12 & 4 & 5 & 11 & 9 & 6 \\
\hline 11 & 7 & 12 & 10 & 3 & 4 & 6 & 1 & 2 & 9 & 5 & 8 \\
\hline 12 & 10 & 11 & 7 & 1 & 2 & 9 & 3 & 4 & 6 & 8 & 5 \\
\hline
\end{tabular}

६ Retrógrado Inversão $\rightarrow$

\begin{tabular}{|l|l|l|l|l|l|l|l|l|l|l|l|}
\hline 1 & 7 & 3 & 10 & 12 & 9 & 2 & 11 & 6 & 4 & 8 & 5 \\
\hline 7 & 11 & 10 & 12 & 9 & 8 & 1 & 6 & 5 & 3 & 2 & 4 \\
\hline 3 & 10 & 1 & 7 & 11 & 6 & 4 & 12 & 9 & 2 & 5 & 8 \\
\hline 10 & 12 & 7 & 11 & 6 & 5 & 3 & 9 & 8 & 1 & 4 & 2 \\
\hline
\end{tabular}




\begin{tabular}{|l|l|l|l|l|l|l|l|l|l|l|l|}
\hline 12 & 9 & 11 & 6 & 5 & 4 & 10 & 8 & 2 & 7 & 3 & 1 \\
\hline 9 & 8 & 6 & 5 & 4 & 3 & 12 & 2 & 1 & 11 & 10 & 7 \\
\hline 2 & 1 & 4 & 3 & 10 & 12 & 8 & 7 & 11 & 5 & 9 & 6 \\
\hline 11 & 6 & 12 & 9 & 8 & 2 & 7 & 5 & 4 & 10 & 1 & 3 \\
\hline 6 & 5 & 9 & 8 & 2 & 1 & 11 & 4 & 3 & 12 & 7 & 10 \\
\hline 4 & 3 & 2 & 1 & 7 & 11 & 5 & 10 & 12 & 8 & 6 & 9 \\
\hline 8 & 2 & 5 & 4 & 3 & 10 & 9 & 1 & 7 & 6 & 12 & 11 \\
\hline 5 & 4 & 8 & 2 & 1 & 7 & 6 & 3 & 10 & 9 & 11 & 12 \\
\hline
\end{tabular}

- Retrógrado invertido

Como existem 12 notas na escala cromática, Boulez foi obrigado a criar escalas com 12 valores nos parâmetros de:

- duração: de uma a 12 fusas; a cada 78 fusas $(1+2+3+\ldots+12=78$ fusas) encerra-se uma série de durações;

- dinâmica:

$\begin{array}{llllllllllll}1 & 2 & 3 & 4 & 5 & 6 & 7 & 8 & 9 & 10 & 11 & 12 \\ \text { pppp } & p p p & p p & p & \text { Quasi } p & m p & m f & \text { Quasif } & f & f f & f f f & f f f f\end{array}$

- articulação:

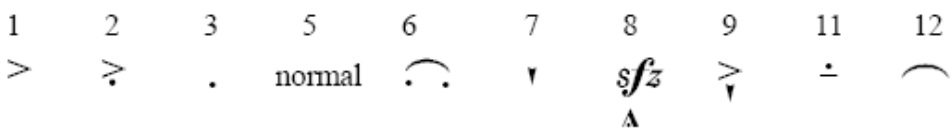

(Os números 4 e 10 não ocorrem nas diagonais escolhidas por Boulez para ordenar as articulações, como será visto adiante.)

Um grau de dinâmica e um tipo de articulação são válidos para uma série inteira de alturas. A sucessão das séries de alturas e das de durações também é serializada: no primeiro piano, por exemplo, enquanto as séries originais de alturas $(\mathrm{O})$ são apresentadas na ordem da Inversão 1, ou seja, O mib, O mi, O lá etc., as séries de durações correspondentes aos números dos Retrógrados Invertidos (RI) são apresentadas na ordem do Retrógrado Invertido 1, ou seja, RI 1 (12, 11,9 , etc.), RI 2 (11, 12, 6 etc.) e assim sucessivamente.

Todas as séries acima mencionadas percorrem as células das tabelas em sentido horizontal. As séries de dinâmicas e de articulações, por outro lado, percorrem-nas em diagonal: as dinâmicas nas diagonais a (12, 7, 7 etc.), b, c (2, $3,1,6,9,7,7,9,6,1,3,2)$ e d (7, 3, 1 etc.).

Dois outros parâmetros não são serializados, sendo portanto deixados ao livre arbítrio do compositor: o registro - em quais oitavas as notas das séries são 
distribuídas - e a densidade - quantidade de séries apresentadas simultaneamente. O quadro a seguir resume os dados expostos até aqui:

Tabela 2. Quadro de serializações de Structures la de Pierre Boulez

\begin{tabular}{|l|l|l|l|}
\hline Instrumento & Parâmetro & Parte A (c. 1-64) & Parte B (c. 65-115) \\
\hline Piano I & Altura & O ordenadas segundo I 1 & RI ordenadas segundo RI 1 \\
& Duração & RI ordenadas segundo RI 1 & I ordenadas segundo RO 1 \\
& Dinâmica & Diagonal a & Diagonal c \\
& Articulação & Diagonal B & Diagonal D \\
\hline Piano II & Altura & I ordenadas segundo O 1 & RO ordenadas segundo RO 1 \\
& Duração & RO ordenadas segundo RO 1 & O ordenadas segundo RI 1 \\
& Dinâmica & Diagonal b & Diagonal d \\
& Articulação & Diagonal A & \\
\hline
\end{tabular}

III.

Provavelmente a argumentação em defesa da organização serial da duração mais citada seja um famoso artigo de Karlheinz Stockhausen, “... wie die Zeit vergeht...“ (Stockhausen, 1963, p. 99-139). Este artigo é, entretanto, muito mais uma justificativa dos métodos seriais empregados em obras como Gruppen (1955-1957) e Zeitmaße (1956) do que uma reflexão profunda sobre o tempo musical.

Posteriormente, Gottfried Michael König expôs de maneira mais didática tais procedimentos de serialização. ${ }^{1}$ O ponto a ser relevado é o sistema desenvolvido para projetar as proporções dos intervalos das séries de alturas para o campo das durações.

Primeiramente, o compositor cria uma escala logarítmica de andamentos entre $\mathrm{h}=60 \mathrm{e} \mathrm{h}=113,3: 60,63,3,67,4$ etc. Estes andamentos, bem como as proporções numéricas entre eles, correspondem às proporções encontradas entre as notas de uma escala cromática no âmbito de uma sétima maior - por exemplo,

\footnotetext{
${ }^{1}$ Koenig, Gottfried Michael. Op. cit. Para uma crítica ao jargão e aos erros conceituais do artigo de Stockhausen, ver: Fokker, Adriaan D. "Wozu und warum? Fragen zur neuen Musik". die Reihe VIII. Rückblicke. Ed. por Herbert Eimert e Karlheinz Stockhausen. Viena: Universal Edition, p. 62-72, 1962.
} 
entre lá 3 e sol\# 4. Distribuindo-os em uma série dodecafônica nessa oitava, temos:

Exemplo 2. Série de Gruppen em uma oitava

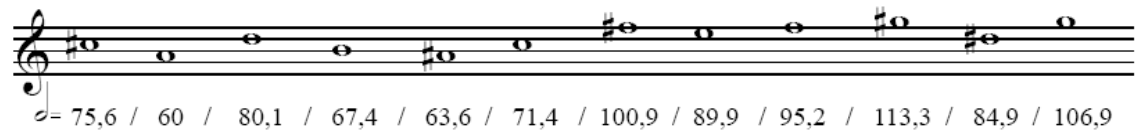

Repare-se que os andamentos são estipulados em relação à mínima. Se uma nota da série for disposta em outra oitava, a marcação metronômica permanece idêntica, mas a unidade de tempo seria outra. Por exemplo: entre lá 3 e sol\# 4 a unidade de tempo é a mínima; entre lá 4 e sol\# 5, semínima; entre lá 2 e sol\# 3 , semibreve. Distribuindo-se as notas da série por vários registros, temos:

Exemplo 3. Série de Gruppen distribuída em várias oitavas.

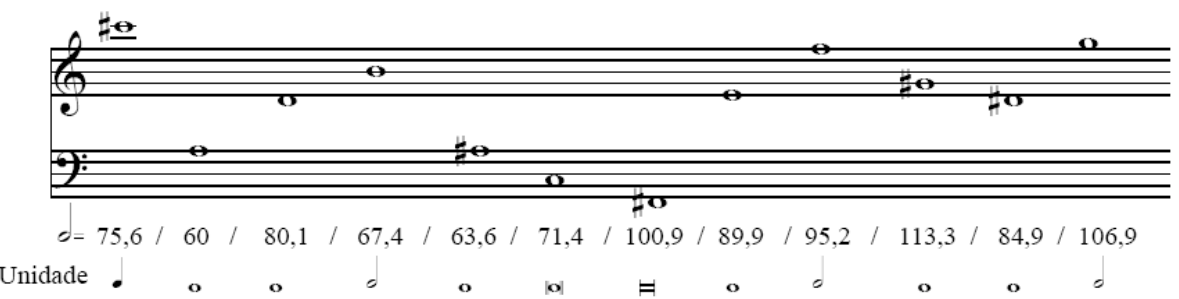

No passo seguinte, o compositor escreve as proporções dos intervalos tal qual ocorridos acima:

Exemplo 4. Série de Gruppen com proporções intervalares

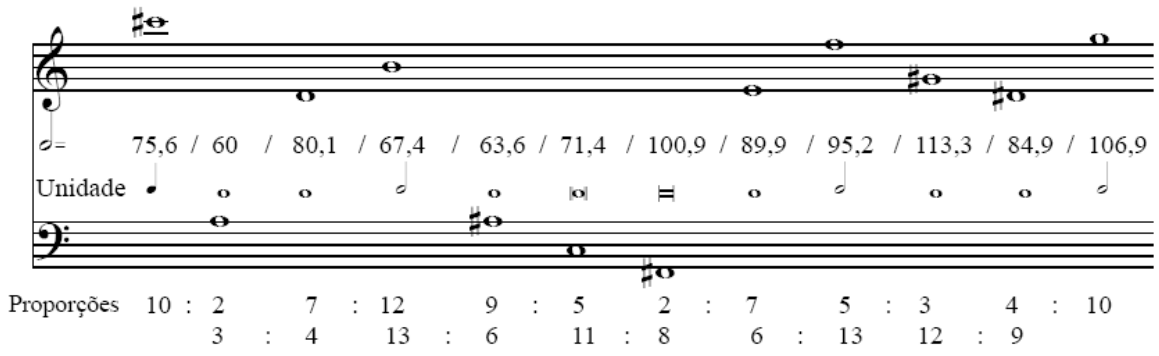


Projetando temporalmente essas proporções, unidades de tempo e marcações metronômicas, é possível estabelecer diversas extensões de tempo. O próximo passo é preencher essas extensões temporais com eventos sonoros (vide Ex. 5).

Essa estratégia de projeção temporal é, sem dúvida, uma expansão matemática de procedimentos que podem ser constatados já em The Unanswered Question de Charles Ives e no segundo episódio da Danse sacrale de Igor Stravinsky: estratos sonoros se justapõem e/ou superpõem estabelecendo menores ou maiores graus de densidade. No caso da peça de Stockhausen, ocorre frequentemente a superposição de andamentos diferentes entre si.

Exemplo 5. Projeção rítmica das proporções intervalares do exemplo 4
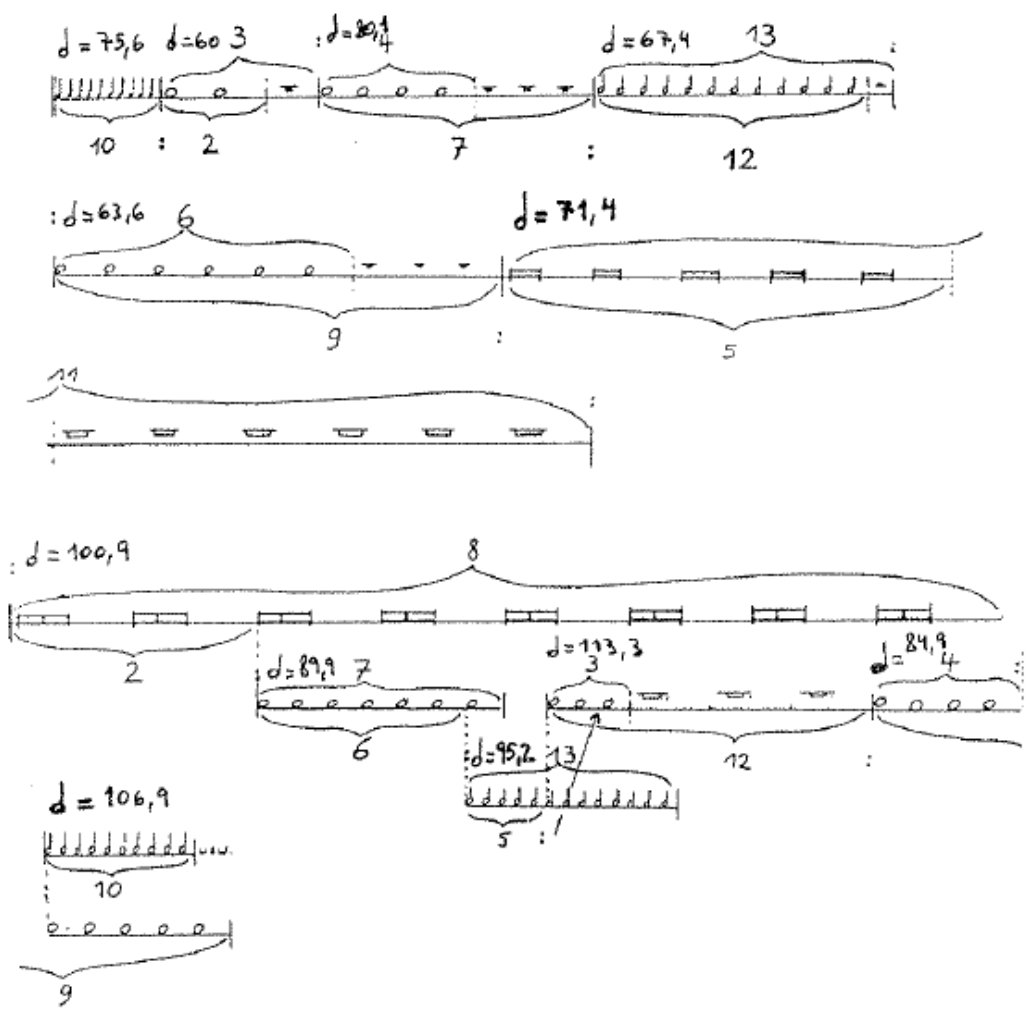
Um outro objetivo aqui, entretanto, trata de identificar a origem de alguns dos argumentos que Stockhausen expõe nesse texto.

Um primeiro e irônico indício para essa tarefa pode ser detectado nos apóstrofos usados por Elliott Carter em um de seus textos: "O livro de [Henry] Cowell New Musical Resources contém um capítulo que trata da associação de proporções de intervalos de altura com proporções de andamento de um modo que foi 'descoberto' mais tarde por certos europeus" (Carter, 1997, p. 79). Esse livro de Cowell foi publicado em 1930. Abaixo são comparados alguns dos argumentos de Cowell e de Stockhausen. Logo no início da segunda parte, "Rhythm", de seu livro, Cowell sugere a projeção de proporções intervalares de uma série harmônica para o parâmetro da duração:

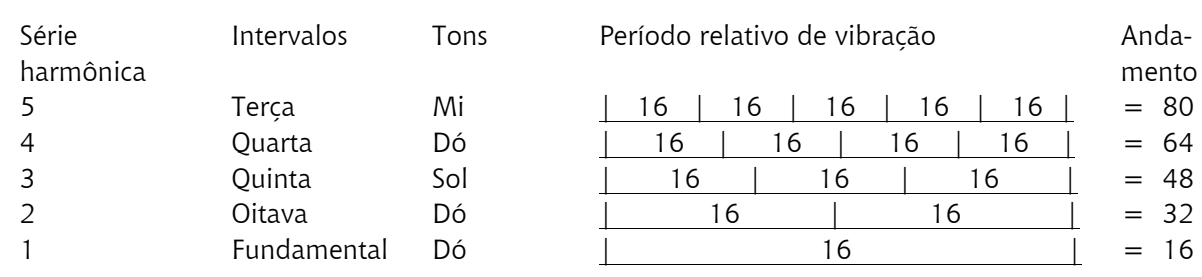

Examinando a coluna à direita, verificamos que as linhas representam graficamente o tempo de um segundo, no qual ocorrem as vibrações do tom fundamental 16, as da oitava 32, as da quinta 48 e assim sucessivamente. [...] Agora, se eliminarmos os dois dós mais graves, verificamos que os tons do acorde simples sol, dó e mi vibram na relação de 48, 64 e 80 no memso intervalo de tempo. [...] O resultado, como mostrado graficamente, é que, enquanto que em nenhum momento no decorrer do segundo de tempo as vibrações coincidem, no final desse período todas as vibrações coincidem. $[\ldots]$

Se [...] desejarmos representar graficamente o resultado de três partes que dividiriam uma semibreve, de maneira idêntica, em três, quatro e cinco partes respectivamente, deveríamos ter um diagrama de forma exatamente similar (Cowell, 1930 [1996], p. 47-48).

Exatamente a mesma argumentação pode ser encontrada no artigo de Stockhausen (1963, p. 108-112), embora este apresente a subdivisão até 12 partes da unidade de tempo, respectivamente da série de harmônicos, e não até cinco partes, como Cowell. 
Como geralmente admitido, Stockhausen confunde os conceitos de infrasom e ritmo quando ele escreve:

Até uma duração de fase de cerca de $1 / 16$ de segundo podemos ouvir os impulsos separadamente; até aí falamos de 'duração' [...] Se a duração de fase for gradativamente reduzida até 1/32 de segundo, os impulsos não são, então, mais perceptíveis separadamente; [...] percebe-se a duração de fase como 'altura' do som (1963, p. 100).

O mesmo erro "poético" é encontrado em Cowell:

Existe um instrumento acústico bem conhecido que produz um som interrompido por silêncios [a sirene]. Quando os silêncios entre os sons não ocorrem tão rapidamente, o resultado é um ritmo. Quando as interrupções no meio do som são aceleradas, no entanto, elas produzem em si uma nova altura [...] (1930[1996], p. 51).

Como a acústica ensina, as alturas abaixo de 16 hertz não são percebidas pela audição humana. Elas existem como tal, são chamadas infrassom e não têm nenhuma relação físico-acústica com valores rítmicos, ou seja, durações. Se eu percuto o tampo da mesa à minha frente duas vezes por segundo, eu não estou, obviamente, produzindo um infrassom de dois hertz!

Ambos os autores sugerem projetar a proporção do meio tom da escala cromática para uma escala de 12 andamentos, de tal forma que o $12^{\circ}$ andamento seja duas vezes mais rápido que o primeiro. As escalas de andamentos sugeridas podem ser comparadas abaixo, sendo que a de Cowell está na linha superior e a de Stockhausen na inferior:

$\begin{array}{llllllllllll}60 & 642 / 7 & 671 / 2 & 72 & 75 & 80 & 84 & 90 & 96 & 100 & 1121 / 2 & 120 \\ 60 & 63,6 & 67,4 & 71,4 & 75,6 & 80,1 & 84,9 & 89,9 & 95,2 & 106,9 & 113,3 & 120\end{array}$

Ocorre aqui, em verdade, uma mixórdia de premissas quando ambos os compositores defendem, por um lado, uma projeção rítmica de proporções intervalares não-temperadas e, por outro lado, algumas páginas adiante, sugerem a projeção de proporções logarítmicas, ou seja, temperadas, da escala cromática para uma tabela de andamentos. 
Até mesmo o "teclado de durações" (Dauern-Klavier) que Stockhausen prevê, foi sugerido por Cowell 27 anos antes. O primeiro escreve:

[ao piano] pressiona-se uma tecla, e, conforme a tecla abaixada, define-se a altura: uma corda do piano vibra, então, periodicamente em uma determinada duração de fase e, de fato, tão longamente quanto se mantém o dedo sobre a tecla. Agora imaginemos o contrário: abaixa-se uma das teclas e desencadeia-se um mecanismo que mede uma duração definida do som; e, através de uma pressão distinta sobre a tecla, determina-se a altura, ou seja, a duração de tempo da fase isolada (Stockhausen, 1963, p. 102).

\section{E Cowell:}

É muito provável que um instrumento possa ser projetado que produziria mecanicamente uma proporção rítmica [...] Por exemplo, suponha que pudéssemos ter um teclado no qual, quando um dó fosse tocado, um ritmo de oito soasse; quando um ré fosse tocado, um ritmo de nove; quando um mi fosse tocado, um ritmo de dez (1930[1996], p. 65-66).

Como demonstrado, Stockhausen apropria-se de ideias de Cowell sem mencionar seu nome. A intenção aqui não é, de forma alguma, renegar a inestimável contribuição de Stockhausen para a teoria da composição dos anos 1950, mas sim, nesse caso específico, desvendar a verdadeira origem dos conceitos apropriados por Stockhausen.

\section{IV.}

Pierre Boulez, por seu turno, faz a seguinte observação autocrítica sobre a fase inicial da música serial da década de 1950: "Quando nós começamos a estender a série para todos os componentes do fenômeno sonoro, nós nos lançamos de corpo e alma - antes, de cabeça e alma - sobre os algarismos, misturando desordenadamente matemática e aritmética elementar"(Boulez, 1963, p. 22). 
Após sua fase serial rigorosa, ele desenvolveu métodos mais flexíveis para ordenar as durações, sendo que a influência de Olivier Messiaen não pode ser ocultada:

[...] uma série de durações pode sofrer modificações de três categorias: [...] 1. Fixa: conservamos as proporções do original multiplicando-o ou dividindo-o por um mesmo valor numérico, o que nós chamamos de aumentação ou diminuição [...] 2. Móvel não-evolutiva: modificamos as proporções do original adicionando-Ihe ou suprimindo-lhe um valor fixo; ao invés de termos uma progressão geométrica, tal qual precedentemente, teremos uma progressão aritmética [...] 3. Móvel evolutiva: modificamos as proporções do original por um valor variável que é função fixa ou móvel de seus constituintes, pontuando, por exemplo, todos os valores [...] (1963, p. 57-58).

Para uma série simples de algarismos, por exemplo 1, 4, 7 e 10, Boulez prescreve duas possibilidades básicas: ou ela pode multiplicar um valor rítmico básico, por exemplo a semicolcheia, de modo a se obter um conjunto de valores rítmicos, ou ela pode subdividir um determinado valor rítmico básico, por exemplo a mínima, de modo a se obter um conjunto de subdivisões desse valor rítmico básico (1963, p. 58-59). Para se dispor os valores, respectivamente as subdivisões, em relação uns com os outros, Boulez sugere três possibilidades:

Resta-me, agora, dispor esses valores uns em relação aos outros, em outros termos, escrever uma distribuição no interior do campo de duração definido pelo valor mais longo [...] Três tipos de distribuições são possíveis: simétrico, assimétrico, combinado simétrico/assimétrico. A distribuição simétrica é regular se ela ocorre em relação a um eixo central [ver letra "a" no ex. 1], [...] e também quando se toma como eixos o início ou o fim do som mais longo [ver letra "b" e "c" no ex. 1] [...]

Notemos que, em relação a um eixo mediano obtemos uma outra forma de distribuição [ver letra "d" no ex. 1] [...]

Naturalmente é possível combinar esses perfis elementares dois a dois, três a três ou quatro a quatro para obter blocos mais variados [ver letra "e" no ex. 1] $[\ldots]$

A distribuição simétrica será irregular, se ela ocorrer em relação a um eixo qualquer - eixo direito ou oblíquo [ver letra "f" e "g" no ex. 1] [...]

[...] A distribuição será assimétrica quando nenhum eixo puder reparti-la [vide Ex. 2] (1963, p. 59-60). 
Os valores rítmicos básicos dos exemplos acima podem, ainda, ser subdivididos, de forma a se criar estruturas mais complexas. A avaliação de Boulez sobre esses procedimentos chega a ser entusiástica:

Assim, qualquer que seja o ponto de partida, os dois processos [proporções de divisão em um bloco de duração e aplicação de uma categoria superior de distribuição aos blocos de divisão] se complementam para criar um conjunto extremamente rico de organizações do tempo, assim como no que concerne às micro e macroestruturas.. A utilização racional da oposição entre multiplicação e divisão da unidade originará, além disso, contrastes surpreendentes graças à gama bem ampla de valores postos em jogo (1963. p. 62).

Ex. 6. Distribuições simétricas de valores rítmicos segundo Boulez
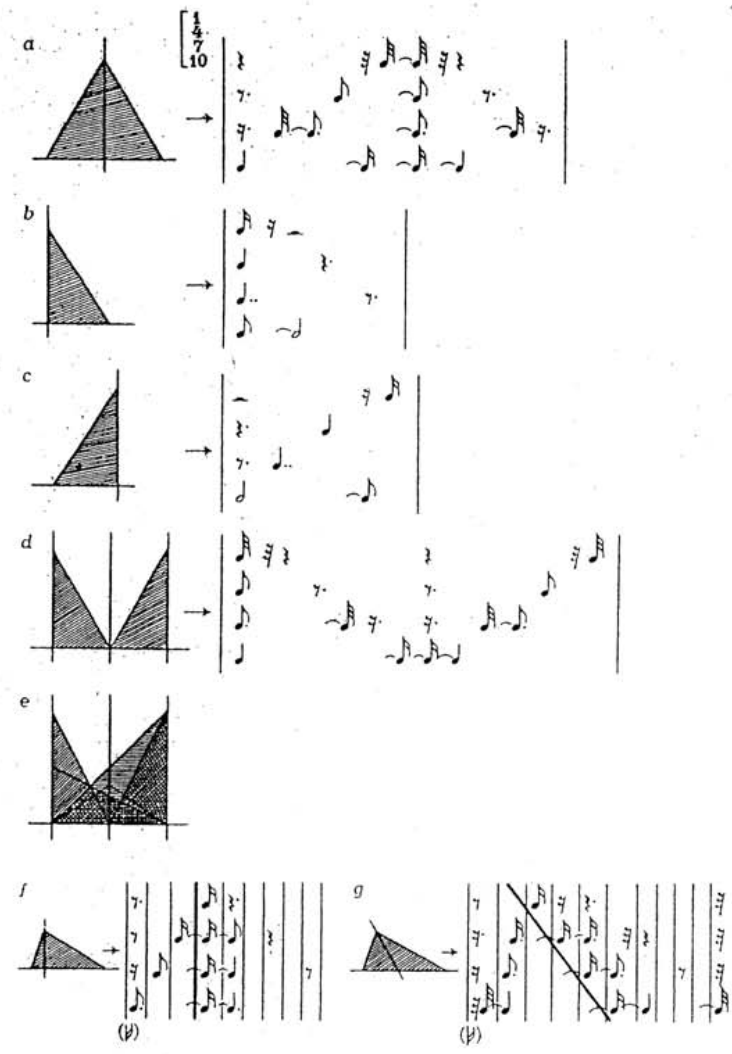
Ex. 7. Distribuição assimétrica de valores rítmicos segundo Boulez

$$
\left|\begin{array}{ccc}
j & A_{y} \\
z & y \cdot d & g \\
y d . . & 7 \\
d & -d
\end{array}\right|
$$

Ainda nesse contexto, é importante resgatar alguns conceitos deste mesmo compositor. Comecemos pela sua definição de andamento: “O andamento (...) é, de alguma maneira, o padrão que dará um valor cronométrico a relações numéricas" (1963, p. 53).

Estas relações poderão ser dispostas em três dimensões temporais: a horizontal - que ordena a sucessão dos sons -, a vertical - que ordena a simultaneidade - e uma categoria intermediária, a diagonal, que abrange todas as inúmeras gradações entre as dimensões horizontal e vertical (1963, p. 25-26).

Finalmente, as duas categorias de tempo musical propriamente dito, às quais se submetem os eventos sonoros quando de sua transposição para os sistemas de notação disponíveis: os tempos pulsado e amorfo.

No primeiro,

as estruturas de duração se referirão ao tempo cronométrico em função de uma marcação, de uma balizagem [...] regular ou irregular, mas sistemática: a pulsação, sendo a menor unidade (mínimo múltiplo comum de todos os valores utilizados), ou um múltiplo simples desta unidade (duas ou três vezes o seu valor) (1963, p. 99).

A princípio, portanto, a utilização de compassos tradicionais com seus valores rítmicos subordinados (a unidade de compasso, a unidade de tempo e subdivisões regulares ou quialtéricas destas duas unidades) é a manifestação mais clara do tempo pulsado, sendo que o compositor pode partir do estabelecimento de um valor mínimo para distribuir os eventos no tempo - por exemplo, a semicolcheia em uma sequência de compassos alternados, tal como 3/16 | 4/16 | 3/16 | 5/16 | etc. -, ou a manutenção de um valor rítmico múltiplo da mesma figura - por exemplo, a semínima no compasso 3/4 ou a mínima pontuada no $6 / 4$. Nestes dois últimos casos, o andamento não deverá ser, obviamente, muito 
lento, senão seria necessário subdividir a unidade de tempo para efeito de contagem.

O próprio Boulez sugere outra terminologia para essas duas categorias de tempo: "O tempo amorfo é comparável à superfície lisa, o tempo pulsado à superfície estriada; eis porque, por analogia, chamarei as duas categorias assim definidas pelo nome de tempo liso e tempo estriado" (1963, p. 100). No tempo liso, portanto, não temos qualquer pulsação para orientar nossa percepção das durações, os eventos sonoros são distribuídos cronométrica ou estatisticamente dentro de uma duração total. No tempo estriado, ao contrário, mesmo que submetida a alterações de andamento ou a alternâncias do valor da unidade de tempo (por exemplo: 3/4 | 9/8 | 3/4 - alternância entre três semínimas e três semínimas pontuadas como figuras representativas da pulsação), a unidade de tempo delineia e orienta nossa percepção das durações. É óbvio que polirritmias complexas grafadas em compassos tradicionais podem camuflar totalmente a apreensão da unidade de tempo, conduzindo nossa percepção auditiva para a categoria de tempo liso.

Mais ou menos na mesma época que Boulez, Iannis Xenakis elaborou uma conceituação ainda mais abrangente, na qual a ordenação serial fosse somente um caso entre outros dentro de um sistema de possibilidades:

[...] se, em razão da complexidade, a causalidade estrita, determinista, que os neo-seriais [na década de 1950] glorificavam, estava perdida, fazia-se necessário substituí-la por uma causalidade mais geral, por uma lógica probabilista que contivesse, como caso particular, a causalidade serial estrita. [...] A estocástica estuda e formula as assim chamadas leis dos grandes números ${ }^{2}$, assim como aquelas dos eventos raros, processos aleatórios etc. Aí está, portanto, como, a partir, entre outras coisas, do impasse das músicas seriais, nasceu em 1954 uma música gerada de acaso que, dois anos mais tarde, eu batizei de "música estocástica". As leis do cálculo das probabilidades entravam na composição por uma necessidade musical (Xenakis, 1994, p. 57).

\footnotetext{
2 Nome dado por Siméon Denis Poisson em 1835 para o assim chamado "teorema de Bernoulli" (Jakob Bernoulli, matemático suíço, 1654-1705) que demonstra que quanto mais cresce o número de tentativas possíveis de determinar a ocorrência do acontecimento A, a freqüência relativa deste mais se aproxima do valor de sua probabilidade.
} 
As suas reflexões e pesquisas formam uma contribuição imprescindível, nas décadas seguintes, para a assim chamada música assistida por computador.

\section{Conclusões}

Como pôde ser constatado, a origem da serialização rítmica aplicada por compositores norte-americanos e europeus após a Segunda Guerra Mundial está nas reflexões musicais feitas por Henry Cowell na década de 1920 e publicadas em seu livro New Musical Resources de 1930. A partir de e graças a suas reflexões, bem como a tentativas iniciais de Milton Babbitt e Olivier Messiaen, compositores europeus, como Karlheinz Stockhausen e Pierre Boulez, entre outros, puderam expandir a aplicação de estratégias de serialização a outros parâmetros musicais. Após um curto período de aplicações seriais integrais através de simples tabelas numéricas, houve uma flexibilização desse pensamento com 0 desenvolvimento de tabelas de categorias sonoras ou texturais que foram, então, serializadas, interrelacionadas em redes de similaridade e dissimilaridade e, finalmente, aplicadas ao processo composicional.

Sem dúvida, as discussões acaloradas em torno do serialismo integral são coisas do passado. Entretanto, ainda testemunhamos as consequências do pensamento serial em muitas das manifestações musicais de hoje - e não só em obras de compositores da assim chamada New Complexity, como Brian Ferneyhough, Claus-Steffen Mahnkopf e Klaus K. Hübler. A diluição gradativa de conceitos e estratégias seriais integrais pode atingir até mesmo aqueles compositores mais desavisados do século XXI.

Pode-se perguntar também, se determinadas correntes estético-musicais teriam brotado com tanto ímpeto, se não como uma espécie de reação - não no sentido político! - à divulgação e mesmo imposição dos padrões composicionais do serialismo integral. Nesse contexto, podem ser mencionados o minimalismo norte-americano, a assim chamada escola polonesa, o neoexpressionismo alemão e o espectralismo francês. 
Além disso, o serialismo integral pode ser visto como, talvez, um dos últimos estágios da história do trabalho temático, entendido aqui como processo de variação em seu sentido mais amplo e radical. Após o serialismo integral, as incorporação e exploração de todas as possibilidades tímbrico-instrumentais era inevitável. Daí surgiram nomes como Giörgy Ligeti e Helmut Lachenmann, por exemplo. Mesmo em compositores dos primórdios do serialismo integral pôde ser observado, nas últimas décadas do século XX, esse interesse específico nessas incorporação e exploração.

\section{Referências}

BOULEZ, Pierre. Penser la musique aujourd'hui. Genebra: Éditions Gonthier, 1963. CARTER, Elliott. "Expressionism and American Music" (1965/1972). In: Collected Essays and Lectures, 1937-1995. Nova edição em brochura. Ed. por Jonathan W. BERNARD. Rochester: University of Rochester, 1998, p. 72-83. . "Time Lecture" (1965/1994). Idem, p. 313-318.

COWELL, Henry. New Musical Resources (1930). Com notas e um ensaio de David Nichols. Cambridge etc.: Cambridge University Press, 1996.

FOKKER, Adriaan D. "Wozu und warum? Fragen zur neuen Musik". die Reihe VIII. Rückblicke. Ed. por Herbert Eimert e Karlheinz Stockhausen. Viena: Universal Edition, p. 62-72, 1962.

KOENIG Gottfried Michael. "Kommentar". die Reihe VIII. Rückblicke. Ed. por Herbert Eimert e Karlheinz Stockhausen. Viena: Universal Edition, p. 73-92, 1962.

KOSTKA, Stefan. Materials and Techniques of Twentyth-Century Music. $3^{\mathrm{a}}$ ed. Upper Saddle River: Pearson Prentice Hall, 2006.

LIGETI, Giörgy. "Pierre Boulez". die Reihe IV. Ed. por Herbert Eimert e Karlheinz Stockhausen. Viena, Universal Edition, p. 38-63, 1958.

STOCKHAUSEN, Karlheinz (1963). “... wie die Zeit vergeht...” (1957). In: Texte zur elektronischen und instrumentalen Musik, Bd. 1: Aufsätze 1952-1962 zur Theorie des Komponierens. Ed. por Dieter Schnebel. Colônia: Verlag M. DuMont Schauberg, 1963, p. 99-139.

VALLAS, Léon. Claude Debussy et son temps. Paris: Éditions Albin Michel, 1958.

XENAKIS, lannis. "Éléments sur les procédés probabilistes (stochastiques) de la composition musicale" (1962). In: Kéleütha. Com prefácio e notas de Benoît Gibson. Paris: L'Arche, 1994, p. 54-66. 